\title{
María del Pilar Fernández Deagustini y Graciela C. Zecchin (Coordinadoras). Cuadernos de trabajos prácticos. Serie: mitos del teatro de Esquilo: Las danaides. La Plata: EDULP, 2020
}

\author{
Mariana Franco San Román \\ CONICET-Instituto de Filología Clásica, Facultad de \\ Filosofía y Letras, Universidad de Buenos Aires, Argentina \\ mariana.franco.7@gmail.com \\ D http://orcid.org/0000-0003-4321-1505
}

Ante la escasez de recursos didácticos para el estudio del griego antiguo en lengua española, Cuadernos de trabajos prácticos. Mitos del teatro de Esquilo: Las danaides procura retomar una serie cuyo origen se remonta al año 1993. Dicho proyecto tenía como objetivo el estudio de los mitos y de la lengua griega a través de pasajes de Biblioteca de Apolodoro. Esta estrategia tiene la potente ventaja de que es factible para el alumno la traducción de textos fuentes desde el primer nivel de griego, aspecto que tradicionalmente ha sido relegado para cursos posteriores.

El presente volumen, a cargo de la Dra. Fernández Deagustini, se centra en su tema de tesis de doctorado, la tragedia Suplicantes de Esquilo, y se divide en dos partes. La primera sección, de carácter teórico, hace un breve recorrido por cuestiones asociadas al mito y a la obra, tales como sus proyecciones, las versiones anteriores a Suplicantes, los modos en que se ha interpretado la historia, el castigo de las danaides en el Hades, la datación y la tetralogía a la que habría pertenecido la tragedia. Asimismo, la autora incluye tres apartados más sobre elementos temáticos que atraviesan la obra esquilea, como son la súplica desde una perspectiva religiosa, la cuestión del género y el matrimonio y, por último, el conflicto entre la institución de la súplica y las leyes seculares.

Por otro lado, la segunda parte incluye el texto griego (Apollod. II.1.3-5) con espacio para la traducción personal del alumno y dos apartados más. Uno se intitula "Preparación del texto", que incluye el significado de las formas verbales y nominales, así como de las preposiciones, adverbios y conjunciones. Cabe aclarar que no se provee toda la información morfológica, la cual se espera que los alumnos internalicen durante el curso, sino que se asemeja a un léxico, al incluir el significado de la palabra y el modo en que ésta es enunciada en un diccionario. Asimismo, se han marcado con asterisco aquellos elementos que puedan generarle mayor dificultad al alumno para su resolución y en los que la orientación del docente pueda ser requerida. El último apartado que integra esta sección es un "Índice de personajes y nombres propios", el cual sigue una doble organización: según el parágrafo y en orden alfabético.

Para concluir, la obra reseñada es de una enorme utilidad para el proceso de enseñanza y aprendizaje de la lengua griega clásica, y presenta una gran originalidad: se trata de una publicación integral que, con la ventaja de focalizarse en una obra específica, permite acompañar al alumno desde todo punto de vista, tanto a nivel teórico cuanto práctico. Asimismo, es de destacar que es de acceso libre desde el sitio del SEDICI - 
Repositorio de la Universidad Nacional de La Plata, lo que facilita enormemente su adquisición, no sólo para los cursos de griego antiguo de dicha Universidad, sino para el empleo de docentes de otros establecimientos. 